\title{
Designing A Refrigeration and Heat-Removal System for Rapid Detector Based on Freezing Point
}

\author{
X.T. Yu \\ International College Beijing \\ China Agricultural University \\ Beijing, China, 100083
}

\author{
J. Leng \\ Foreign Language Department \\ China University of Geosciences (Beijing) \\ Beijing, China, 100083
}

\author{
X.B. Guo \\ School of Engineering and Technology \\ China University of Geosciences (Beijing) \\ Beijing, China, 100083
}

\begin{abstract}
Based on a detection method of freezing point, the paper proposed a simple, reliable, portable, and low-cost refrigeration and heat-removal system. Semiconductor refrigeration was chosen through comparing operating principles and features of three refrigeration solutions. Forced air cooling was then selected through comparing three heat dissipating methods for hot ends of semiconductor chilling. After determining the refrigeration and heat-removal solution, semiconductor refrigeration and heat dissipating by air cooling for the hot ends were selected as erection schemes, with stirring apparatus and condensate water processing unit. Mechanical compression was chosen for fixation through comparing features of three installation methods. It is safe to say that this refrigeration and heat-removal system can be used to rapidly detect the categories and quantities of adulterated milk with accuracy.
\end{abstract}

Keywords-freezing point detection; refrigeration; heat-removal; systematic design

\section{INTRODUCTION}

Milk is of rich nutrition and has become a popular dairy product, and its demand increases with people's raising health consciousness. To make profit, some lawbreakers adulterate water, salt, sucrose and preservative with fresh milk. Such adulterated milk is closely involved with milk drinker health, especially for the young and the aged with weak immunity. Through inspecting freezing point of milk sample to be detected, freezing-point detector can be used to qualitatively and quantitatively detect milk adulteration. A bottle-neck issue for the national products is complex preprocessing, long testing period, and difficult to carry [1]. And the counterpart for the foreign like product is high-cost and inconvenient maintenance [2]. The crux of the matters above lies in its refrigeration and heat-removal system. This paper thus attempts to design a refrigeration and heat-removal system with three characters of simple and reliable structure, portable operating and low-cost, so as to make a rapid and efficient detection of the milk quality possible for freezing- point rapid detector.

\section{Testing PRINCIPAL AND Method}

\section{A. Testing Principals}

The freezing point of pure water is $0^{\circ} \mathrm{C}$, which is higher than milk. When water or other impurities are adulterated with milk, its freezing point will change. The more substance gets adulterated with milk, the more will the freezing point be fluctuated. By testing the freezing point of samples and comparing them with database, we can find out whether milk is adulterated. We can even figure out the category and content of impurities [3]. Our national recommendatory standard is that the freezing point of milk can reasonably fluctuates from $-0.546{ }^{\circ} \mathrm{C}$ to $-0.508{ }^{\circ} \mathrm{C}$. Samples whose freezing point is above $-0.508{ }^{\circ} \mathrm{C}$ or below $-0.546{ }^{\circ} \mathrm{C}$ can be judged as disqualification.

\section{B. Testing Methods}

Refrigerate the liquid samples until their temperature drops below freezing. Then the samples will crystallize, curdle, and give off heat. After temperature rise, the samples will remain constant within a short period, and the temperature is read as the freezing point. Processor can output picture signals of the temperature curve on the display. The samples will be discharged at last through liquid waste processing unit.

\section{DESIGN OF REFRIGERATION SYSTEM}

Three main refrigerating methods available to date for miniature instruments are: vapor compression refrigeration, absorption refrigeration and thermoelectric refrigeration; and whose working diagrams are shown in Figure 1. The cyclic process of vapor compression refrigeration system for small sized device whose refrigerating capacity is less than $25 \mathrm{kw}$ is achieved by the flow of refrigerating fluid, as shown in Figure 1a. Refrigerating fluid 1 flows out from condenser 2 , and then flows in the closed pipeline 3 . When the refrigerating fluid goes through throttle valve 4 , thermal insulation isenthalpic expansion will occur. The cooling is conducted as the evaporation of the refrigerating fluid absorbs heat when it goes 
through evaporator 5. After that, the refrigerating fluid will be compressed by a piston compressor 6 and enter into condenser 2 to cool itself. Vapor compression refrigeration has large refrigerating capacity, good refrigeration effect, and high cost performance. However, the refrigerating fluid, such as Freon, may destroy the ozone layer and pollute the environment.

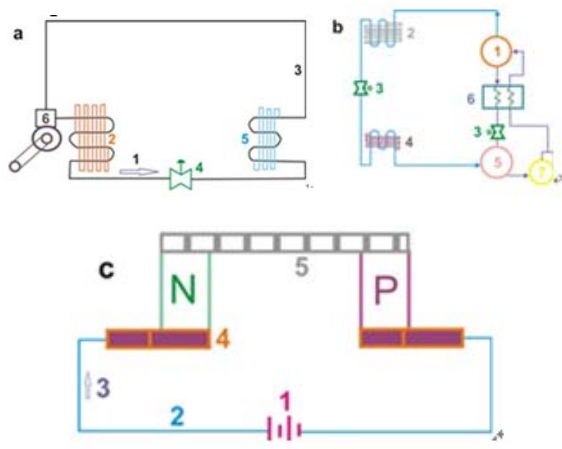

FIGURE I. SCHEMATIC DIAGRAM OF WORKING PRINCIPLE OF COOLING SYSTEMS.

(A) VAPOR COMPRESSION REFRIGERATION (1. REFRIGERATING FLUID; 2. CONDENSER; 3. CLOSED PIPELINE; 4. THROTTLE VALVE; 5. EVAPORATOR; 6. COMPRESSOR.); (B) ABSORPTION REFRIGERATION (1. GENERATOR; 2 . CONDENSER; 3 . THROTTLE VALVE; 4. EVAPORATOR; 5. ABSORBER; 6. HEAT EXCHANGER; 7. SOLUTION PUMP.); (C) THERMOELECTRIC REFRIGERATION (1. POWER SUPPLY; 2. ELECTRIC WIRE; 3 ELECTRON CURRENT; 4. COLD END; 5. HOT END.)

As shown in Figure 1b for absorption refrigeration system, a refrigeration cycle can be formed in this way. Refrigerating fluid is heated in generator 1 , and the isolated refrigerating vapor enters condenser 2 through pipelines, where the vapor condenses into liquid. After the liquid refrigerating fluid is depressurized in throttle valve 3 , the cooling is occurred as the evaporation of the refrigerating fluid absorbs heat when it goes through evaporator 4, where the refrigerating fluid changes from a liquid to a vapor, and then enters the absorber 5. The refrigerating fluid flowing out from generator 1 passes through heat exchanger 6 and is depressurized by throttle valve 3 . After that, it enters the absorber 5 to absorb the vapor of refrigerating fluid. The solution pump 7 allows the refrigerating fluid to reenter generator 1 after it absorbs heat to warm up in heat exchanger 6 . The refrigerating fluid is natural water or ammonia, which is harmless to the environment and atmospheric ozonosphere. Its driven energy can be residual heat, waste heat, and solar energy. However, its shortcomings are small refrigerating capacity, high cost, large energy consumption and bulky set.

Thermoelectric refrigeration system shown in Figure 1c works under action of Peltier Effect: current carriers form an electric current in the conductor. Current carriers are in different energy levels for different materials, so they release energy when moving from high energy levels to low ones. Vice versa, they absorb energy when moving from low energy levels to high ones. In this case, if power supply 1 turns on, the electron current 3 will form in electric wire 2. The thermocouple is composed of P-semiconductor and $\mathrm{N}$-semiconductor materials with conspicuous pyroelectric effects. When the electric current goes through it, the flow direction is $\mathrm{N} \rightarrow \mathrm{P}$ from the thermocouple to layup in upper end. The heat is absorbed and temperature drops, which forms the cold end 4 . If the flow direction is $\mathrm{N} \rightarrow \mathrm{P}$ in the layup of lower end, the heat is released and temperate rises, which forms the hot end 5. Since there is no mechanical motion in thermoelectric refrigeration, it is efficient to work and convenient to use.

The above comparative investigation allows us to choose semiconductor refrigeration. By altering the supply voltage of refrigerator, we can achieve continuous adjustment of refrigerating capacity. By means of wide adjustable temperature range, light weight, and small volume, such refrigeration is also non-hazardous and environmentally friendly, and thus becomes a good candidate applicable for miniature instruments like freezing-point rapid detector.

\section{Design of Heat-Removal System}

During thermoelectric refrigeration, heat-removal effectiveness of the hot end directly affects the semi-conductive refrigeration performance. Only if the heat in hot end is driven away without delay and ensures that the temperature is not too high, the cold end can be continuously refrigerated. Therefore, removing the heat of hot end is a critical point for semiconductor refrigeration. Three main heat-removal methods possible for semiconductor refrigeration are air natural convection, air cooling and water-cooled radiator, and whose operating principles are shown in Figure 2. Figure 2a shows the air natural convection, which installs heat sink 3 at the hot end of semiconductor refrigeration piece 2 . In order to refrigerate, it employs air natural convection to remove the heat of objects under refrigeration into surroundings. With simple structure, the heat-removal efficiency of the method is not so good. Air cooling, shown in Figure 2b, is based on natural convection to remove heat. It installs an axial flow fan at the end of a cooling fin. With simple structure, small volume and low cost, the system is more effective in removing heat. As shown in Figure $2 \mathrm{c}$, water-cooled radiator connects a cold plate 2 to the hot end of semiconductor refrigeration piece 1. Under action of pump 5, water in tank 3 enters the water-cooled tube through water pipe 4. It uses the circular flow of water to remove heat from the hot end of object under refrigeration 6 . Its heat-removal effectiveness is good enough, but suffers from bulky structure and noise from running pump.

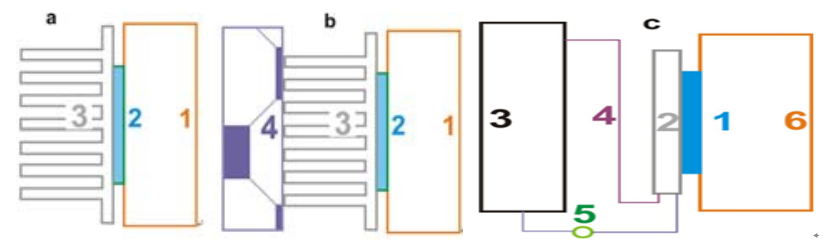

FIGURE II. SCHEMATIC DIAGRAM OF WORKING PRINCIPLE OF HEAT-REMOVAL SYSTEMS

(A) AIR NATURAL CONVECTION (1. OBJECT UNDER

REFRIGERATION 2. SEMICONDUCTOR REFRIGERATION PIECE 3. HEAT SINK); (B) AIR COOLING (1. OBJECT UNDER REFRIGERATION 2 SEMICONDUCTOR REFRIGERATION PIECE 3. HEAT SINK 4. A COOLING FAN); (C) WATER-COOLED RADIATOR ( 1

SEMICONDUCTOR REFRIGERATION PIECE 2. COLD PLATE 3. TANK 4. WATER PIPE 5. PUMP 6. OBJECT UNDER REFRIGERATION) 
As a result, we can see air cooling is superior to the other heat-removal methods applicable for small sized devices like freezing-point rapid detector.

\section{Assembly of Cooling and Heat-removal Module}

Figure 3 exhibits an assembly drawing of cooling and heat-removal system. The core component is semiconductor refrigeration piece 1, and whose cold end can cool samples in cooling pool 2. The hot end of semiconductor refrigeration piece employs air cooling, where heat sink 3 cooperates with cooling fan 5. There are clapboards 4 around cooling pool, and heat sink is separated with cooling pool by insulation boards 6 . Below the cooling pool, there is a collecting tank 7 used to collect condensed water, produced during the cooling process. There is an air-out fan on the back wall of the cabinet 8 , used for removing heat from the hot end.

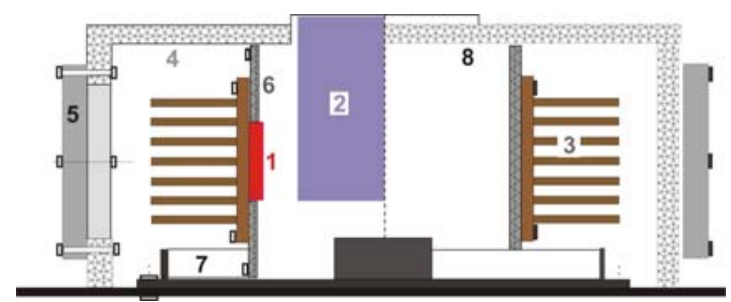

FIGURE III. ASSEMBLY DRAWING OF COOLING AND HEAT-REMOVAL SYSTEM.

\section{(1. SEMICONDUCTOR REFRIGERATION PIECE; 2. COOLING POOL; 3. HEAT SINK; 4. CLAPBOARD; 5. COOLING FAN; 6. INSULATION BOARD; 7. COLLECTING TANK FOR CONDENSED WATER; 8 , CABINET.)}

Three common installation methods are welding, bonding and mechanical compression fixation. The welding method suffers from high cost, inconvenient maintenance, and easy damage of the refrigeration piece during operation. Bonding is simple and convenient to install, but is also difficult to disassemble and maintain, and whose tack coat is easy to age and shed. The reliable mechanical compression fixation is simple to install and convenient to disassemble, and thus becomes our option.

\section{CONCLUSION}

Aiming at current issues for freezing-point rapid detector to milk, this work offers a design for refrigeration and heat-removal system applicable for rapid detector, after introducing testing principle and method of the rapid detector. A comparative investigation of three refrigeration solutions allows us to pick up semiconductor refrigeration in view of rapid refrigeration and simple structure. After comparing working principles and features of three heat-removal methods for hot ends of semiconductor refrigeration piece, air cooling is chosen due to its heat-removal character and working condition. In case that the refrigeration and heat-removal solution is determined, the final design belongs to semiconductor refrigeration and air cooling for removal heat around the hot ends, with stirring apparatus and condensate water processing unit.

\section{ACKNOWLEDGMENT}

This work was supported by college students' scientific research and entrepreneurial action plan project of Beijing.

\section{REFERENCES}

[1] Y.B. Li, Z.J. Zhang, J.S. Li, H.G. Li, Y. Chen, Z.H. Liu, Simple, stable and sensitive electrogenerated chemiluminescence detector for high-performance liquid chromatography and its application in direct determination of multiple fluoroquinolone residues in milk, Talanta. 84(2011) 690-695.

[2] S. Qu, X. Yu, X.J. Liu, P.F. Yu, A design of turbidimetry based rapid microbiology detector, Advanced Materials Research. 662(2013) 758-761.

[3] P.A. Lieberzeit, F.L. Dickert, Rapid bioanalysis with chemical sensors: Novel strategies for devices and artificial recognition membranes, Analytical and Bioanalytical Chemistry, (391)2008 1629-1639. 